\title{
Social Culture Review and Inheritance of Jinzhongdu District in Beijing
}

\author{
Wenjing Fan ${ }^{1, *}$, Sijia Huo ${ }^{2}$ \\ ${ }^{1}$ School of Economics and Management, Beijing Institute of Graphic Communication, Beijing, China \\ ${ }^{2}$ Aerospace Information Research Institute (AIR) under the Chinese Academy of Sciences (CAS), Beijing, China \\ *Corresponding author
}

\begin{abstract}
Beijing used to be called "Ji, Nanjing, Yanjing" and so on. The first time it became capital was when Wanyanliang moved the capital of Jin Dynasty from Acheng, Heilongjiang to Yanjing in 1153. The purpose of this paper is to promote the excavation and inheritance of Beijing's ancient capital resources and prosper the capital culture. Firstly, the paper verified the Jinzhongdu's location, compared it with the location of Liaoning Nanjing, Yuandadu, and Beijing City of the Ming and Qing Dynasties, and explored the location principles of Jinzhongdu. Secondly, starting from the period of Youzhou in the Tang Dynasty, the paper reviewed the cultural and economic development of the area where Jinzhongdu is located, and explored the background of the formation of Jinzhongdu culture. Again, the paper illustrated the important social thoughts of Jinzhongdu and their influences on later generations.
\end{abstract}

Keywords: Jinzhongdu, Social Culture, Review, Inheritance

\section{北京金中都地区社会文化回顾与传承研究}

\author{
范文静 ${ }^{*}$, 霍斯佳 ${ }^{2}$
}

1 北京印刷学院经济管理学院, 北京, 中国

2 中国科学院空天信息创新研究院, 北京, 中国

*通讯作者

\section{中文摘要}

北京古称“䔡、南京、燕京”等，首次成为首都是从1153年金完颜亮将金代国都从黑龙江阿城迁都至燕 京开始。为了助推北京古都文化资源的挖掘与传承, 繁荣北京首都文化, 文章首先考证了金中都位置, 将金中都位置与辽南京、元大都、明清北京城进行对比，探究金中都城的选址原则。其次，文章从唐 幽州时期开始，回顾了金中都所在地区的文化经济发展状况，探究金中都文化形成的背景。再次，文 章对金中都重要的社会思想及对后世的影响进行举例阐述。

关键词: 金中都; 社会文化; 回顾; 传承

\section{1. 引言}

北京自古以来就是北方重要的方国之都、地方州 郡。《史记·周本记》载: “周武王姬发灭商, 封黄帝之 后于蓟, 封召公于燕。”䔡即今北京广安门附近, 燕即 今北京房山琉璃河附近。北京处于南北各民族交往的枢 纽地位, 具备易守难攻的天然地理环境, 物产丰富。在
金时已有丰厚的经济、文化基础和基本完备的城市基础 设施。公元1141年宋金“绍兴议和”，宋向金称臣，并划 定东西以“淮河中流——大散关”为分界线, 以南属宋,

以北属金。许元宗《宣和乙巳奉使金国行程录》记载辽 南京城 (即燕京) “形势雄杰, 真用武之国, 四明四镇 皆不及也”[1]。燕京位置的重要性可见一斑。“绍兴议和” 宋割让唐州 (今河南唐河)、邓州（河南邓州）以及商 州 (今陕西商县) 、秦州 (今甘肃天水) 的大半，每年 向金进贡白银二十五万两，绢二十五万匹。源源不断的 
物质补偿使得金在华北的统治日趋稳定，为了进一步维 护政权稳定, 金统治者决定将都城从北方苦寒的阿城南 迁至燕京。金海陵王完颜亮贞元元年（1153年）迁都燕 京, 将“燕京”改称“中都”, 开启了北京作为都城的历史, 称“金中都”。金中都文化是北京古都文化的重要内容, 2020年4月 《中共北京市委关于新时代繁荣兴盛首都文 化的意见》中强调传承源远流长的古都文化, 彰显中华 优秀传统文化的时代价值, 其中提到保护好金中都遗 址。

\section{2. 金中都遗址及金代布局}

金中都遗址位于今北京西城、丰台一带, 略呈长方 形, 是在辽南京城的基础向东、西、南三面各扩展3里 而成, 北面仍沿袭辽南京北墙未变。金中都城东南角, 在今北京南站路东的四路通路; 东北角在宣武门内翠花 街; 西北角在军事博物馆南的黄亭子; 西南角在凤凰嘴 村。金中都与元大都没有交集, 与辽南京有大面积交集, 与明清北京城有部分交集（示意图见图1）。

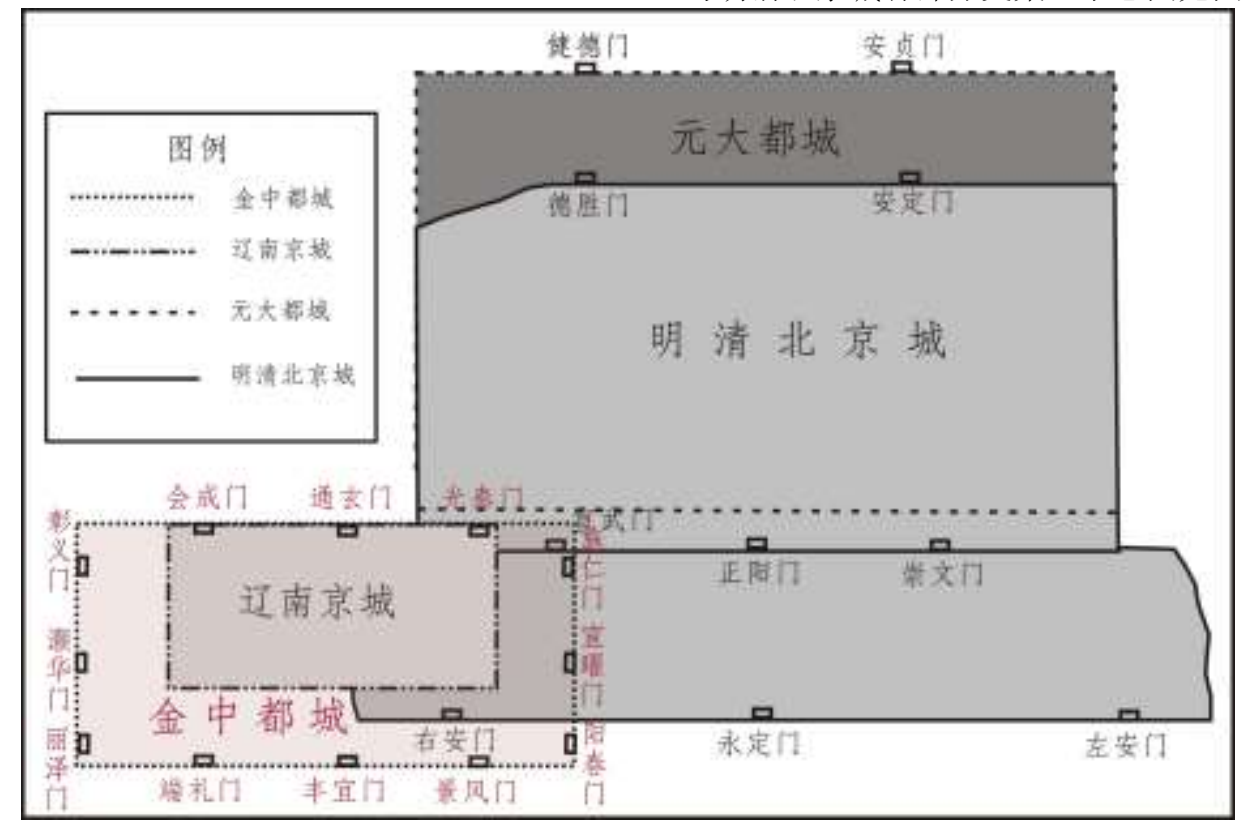

（根据辽史、金史元史、清史都城位置对比绘制）

图1 金中都与元大都、辽南京、明清北京城的位置关系示意图

金中都城由外城、皇城、宫城三部分组成, 城内水 系发达，苑固齐具，街道坊巷布局规整。外城周长约 35 里, 方形, 四至范围大致如下: 东城垣, 四路通至宣武 门内翠花街南北一线; 西城垣, 凤凰嘴村至军事博物馆 南黄亭子南北一线; 南城垣, 凤凰嘴村至四路通村的东 西一线; 北城垣, 唐幽州城和辽南京旧城的北城墙址。 皇城, 基址位于广安门南滨河一带, 周围3里, 共有城 门四座: 东为宣华门、南宣阳门, 西玉华门, 北为拱辰 门。宫城在皇城后部, 位于金中都中心, 共有殿36座, 还有众多的楼阁和园池名胜。

从都城建设上看, 海陵王顺应历史发展需要迁都燕 京，这不但为金朝世代兴盛（后继者世宗、章宗统治50 年) 打下了基础, 也奠定了后世（元、明、清）作为首 都的根基。金代海陵、世宗、章宗三代60年对中都的建 设, 将北京推进到了名副其实的首都地位。城市性质的 改变, 帝王郊苑的规模逐渐形成, 使中都成为一座极其 奢丽的为帝王服务的城市[2]。宋人周麟之于海陵王正隆 四年（1159年）出使金朝之后所撰写的《海陵集》一书 中有这样的描述: “燕京城内地大半入宫禁, 百姓绝少, 宫阙壮丽, 延亘阶陌, 上切霄汉.......”金中都沿用辽南 京、仿照泣梁城并有所发展和提高, 对后世也产生了深
远影响，元大都、明清北京城平面作“回”字形的布局无 不受金中都的影响，宫殿建制、行宫园林也都被后世沿 用并发挥[3]。

\section{3. 金中都地区文化经济回顾}

\section{1. 唐幽州时期}

燕京, 唐称 “幽州”。据《房山经》记载, 唐幽州 市场有许多行业，如白米行、大绢行、彩帛行、丝帛行、 屠行、炭行、生铁行、磨行、布行、果子行、肉行、染 行、靴行、杂货行、油行等, 经营食品、金属用具、日 用品、纺织品、燃料交易等。唐中叶, 在幽州城北形成 了商业区，称 “幽州市”。可见当时的商业活动已经相 当活跃，资金、人才、商流等的聚集为要素平台搭建奠 定了基础。 


\section{2. 辽南京时期}

燕京在辽时商业进一步发展, 市场繁荣, 税收稳定, 宜居宜业, 这也是海陵王迁都的原因之一。契丹族建辽 之初就充分注意到了燕京的商业功能, 并采取了实际措 施推动该地商业的发展。经过多年经营, 燕京地区的商 业获得长足发展 $[4]$ 。《辽史》卷 48, 《百官志・四》记 载, 南京“多财赋官”, 这从一个侧面表明燕京地区商业 的繁荣，百业兴旺令政府有税可征，政府才会多设“财 赋官”。金初（1125年）北宋许六宗出使金国时, 看到 析津府（今北京西南）“居民棋布，巷端直，列肆者百 室”, “户口安堵, 人物繁庶, 大康广陌皆有条理。…… 城北有互市, 陆海百货萃于其中, 僧居佛宇冠于北方, 锦绣组绮精绝天下, 膏舆、蔬菂、果实、稻粱之类靡不 毕出, 而桑、柘、麻、麦、羊、豕、雉、兔, 不问可知。 水甘土厚, 人多技艺, 民尚气节。秀者则向学读书, 次 则习骑射, 耐劳苦。”一许妄宗《宣和乙巳奉使金国 行程录》[5], 描绘了燕京地区的商业发展状况和人民生 活状况。

\section{3. 金中都时期}

海陵王迁都中都以后，皇室贵族、文武百官及其家 属随从等大量消费性人口一并而致，与此同时，金政府 鼓励居民迁入中都地区, 于是交通运输、住宿餐饮、教 育卫生等各类服务性人口大量聚集在金中都城。金泰和 七年 (1207年) 中都城市总人口达到 40 万人左右。人口 的大量聚集进一步促进了城市商业发展和文化的兴盛。 中都不仅是中都路（金代形成区划制度）地区的中心城 市，也是全国的政治、经济和文化中心。

海陵王迁都燕京后，厉行革新，施行从中央到地方 一系列政治、经济、民族等方面的改革。通过推行汉化、 大力发展文化教育、颁布“正隆官制”，任用各民族官员 等，实现了多民族融合的政局，呈现出“天下太平，四 民安居乐业”的景象。在商业上，宋金之间的贸易交往 十分密切。每年, 从宋输入到金大量茶叶、生姜、食糖、 香药等, 同时又有大量的丝、棉、锦、绢等从金输入到 宋[6]。商品交换的发达, 伴随着货币经济和货币流通的 迅速发展。

金建国之初, 没有独立币制, 主要使用辽、宋旧钱, 直到海陵王时期，才开始发行“交钞”和铜钱，并陆续制 定一系列有关货币发行、流通、回笼等方面的法律法令, 建立起一套比较完备的货币制度[7]。“交钞”共流通80余 年，由最初的“七年为限，纳旧易新”制度到金章宗时期 （1189年）“不限年月行用”可无限期流通，在推动货币 纸币化上具有里程碑式的意义。金代货币研究者大多将 金代货币制度的演变分为三个阶段：从以物易物到货币 交易阶段（1115-1153年）、以钱为主、钱钞并用阶段 （1154-1189年）、货币制度混乱和崩溃阶段（1190-1234 年)。

\section{4. 元大都时期}

元灭金以后，至元四年（约1267年）在金中都东北 角之外开始动工建设元代都城，历时 20 余年建成。至元 二十二年（1285年）诏令规定，官员和富庶商贾可以优 先搬入新城, 多数平民百姓居住在旧城。因此新城和旧 城也有了 “官城”与 “民城” 的区别。虽然旧城（原中 都城）为普通百姓居住之所，但因为人口密集，仍然充 满活力。历史上常用 “南北二城” 指金中都城和元大都 城。元大都继承了金代的许多商业设施, 商业细分更多, 商品贸易更加规范，交易市场划分为米市、面市、菜市、 鞋帽市、柴炭市、铁器市、珠宝市等, 商品种类极大丰 富。

元代大通漕运水道使江南米粮成为元大都粮食供 应的绝对主力, 但元大都周边地区特别是南郊地区也是 保障大都粮食供应的重要生力军。元许有壬《弄田赋》 载:“我朝登三迈五, 南郊畍畍, 有田千亩, 大臣代耕, 岁事修举。”意说: 我朝可謧美三皇五帝时期, 南郊田 地平整, 大量良田, 大臣俸禄富足, 一年农事兴盛。说 明元大都城南郊有大面积农田, 农事兴盛。

\section{5. 明清时期}

明清时期金中都地区泉水丰沛，主要经济产业以灌 溉性种植业为主, 粮食作物主要为水稻, 经济作物有蔬 菜、花卉等。明代时期逐渐形成自然村，村名及村子的 主要经济来源都与水密切相关。“前泥洼”、“后泥洼”、“水 头庄”、“万泉寺”、“玉泉营”、“管头村”等村名记录了村 子与水的关系。《菜户营村村志》记载: “菜户营村明 代成村，因有菜户聚集于此而得名”。明朝后期，菜户 营地区为御膳房嘉蔬属所在地, 负责宫廷蔬菜的挑选、 记录、分配与传送。作为宫廷每日必需品的物流集散地, 这里每日聚集大批供货菜农和负责押运的官员。因为古 时交通不便, 供菜菜农一趟往来常所需数日, 晚间有许 多菜农在此休息, 久而久之, 人们将此地称为“菜户营”。 其周围的三路居、万泉寺、东管头村等直到 20 世纪 80 年 代仍为北京重要的种菜区。

\section{6. 当今时代}

如今金中都现存遗址较少，原来的菜户营、凤凰嘴 等位于村都因为可考的有金中都水关遗址，今为辽金城 垣博物馆，位于丰台区玉林小区凉水河以北，为原址保 护遗址。金代城垣遗址, 现存共3处, 均位于北京丽泽 金融商务区范围内。金代营房遗址，2019年北京丰台区 城市建设中将金代营房就址改名为 “西营街” ，东起金 泽东路, 西止北京西站南路。2013北京市政府在西二环、 南二环、西护城河交界处修建“金中都公园”，是民众了 解北京建都史和金代历史的不二之选。 


\section{4. 金中都文化传承}

\section{1. 社会思想}

\subsection{1. “王者居中”思想:}

“王者居中”思想有文献记载的可以追溯到战国时 期。《荀子》、《吕氏春秋》均有相关记载, 而“王者 居中”思想表现在皇城建设上, 始于金中都, 金修建金 中都扩展辽南京城垣便是为了使皇城居于都城中央。这 种开创性布局改变了汉长安、隋唐洛阳、辽南京宫城处 于都城一隅的格局。中都皇宫主殿大安殿居于宫城中 心, 位置在都城的中轴线上, 这在此前宫城建筑中是少 有的。王者居中的思想均被元明清所采用, 而且更为强 调。

\subsection{2. 五行方位布局:}

金统治者很注意吸收汉族的先进文化，《周易》的 五行思想在金宫城布局和金陵选址上均有重要的指导 作用，并对后世宫城的布局产生深远影响。

金中都宫城分东中西三路。中路按前朝后寝的原则 安排, 东路安排太子宫。按五行说, 东属木, 象征为四 季之春, 主生化过程, 因而太子宫建在东路。紫禁城东 路与金宫城相似, 亦设太子宫于东华门内之东路。元在 西苑东侧建皇宫亦仿自中都。

中都宣阳门东西设文武楼，乃文武楼制之开端。明 奉天殿（后改皇极殿，清为太和殿）左右亦建文武楼, 嘉靖年间改为文昭阁 (清为体仁阁) 和武成阁 (清为弘 义阁）。

明乾清宫与金仁政殿亦近似，亦有披阅奏章、召见 群臣、处理日常政务功能。宫城前有千步廊, 正门是通 天门, 门楼系琉璃瓦顶, 高8丈, 深 11 间, 中间红色五 座门楼, 两侧有垛楼, 东西有左右掖门, 是明清午门的 雏形。

\section{2. 节日文化}

海陵王仰慕汉文化，极力促成女真人汉化。金朝沿 用汉族干支历法，规范了燕京的时间文化。据《大金集 礼》卷 32 《休假》中记载: 立春、春分、寒食、立夏、 三伏、立秋、七夕、等时令均为法定假日，根据节日不 同设置1-3天的假期。金朝用法律的形式确立的这一批节 日, 奠定了北京地区传统节日架构的基础。这些节日经 过八百多年的发展, 与各族人民时间文化的融合, 逐步 形成了北京地域文化的节日系统, 并对全国的节庆安 排，发挥了示范作用 [8]。金朝留下来的传统节日可以用 “三元七重, 四时八节” ( 三元: 上元节、中元节, 下元
节。七重: 正月正、二月二、三月三、五月五、六月六、 七月七、九月九。四时: 春、夏、秋、冬。八节: 立春、 春分、立夏、夏至、立秋、秋分、立冬、冬至。）来概 括，不算其他杂节也有 22 个之多，每月均有 1-2个节日， 传统节日是一笔宝贵的非物质文化遗产，也反映了当时 民众社会生活的丰富多彩。

\section{5. 结束语}

自1153年金完颜亮迁都燕京，至2020年北京已有 867 年的建都史。金中都文化遗产在王朝更迭中不断被 破坏, 保留至今的胗䇣无几。以致如今提起北京的古都 文化，绝大多数人想到的是明清，而其实金中都才是北 京古都文化的起源。北京古都文化是北京首都文化的重 要组成内容, 挖掘好、传承好古都文化具有重要的意义。 文章主要回顾了金中都地区的经济社会发展，从文化形 成的背景角度探究金中都地区主要社会现象及古都文 化特征，但是文章没有从物质层面阐述金中都文化遗 产，金中都物质文化遗产包括金中都水关遗址、金中都 城垣遗址、护城河遗址、园林遗址等，今后研究团队将 从物质文化遗产的角度探讨古都文化资源的保护与传 承。

\section{致谢}

本文为北京社科基金青年项目《北京古都文化资源 挖掘与传承研究——金中都为例》 (18GLC050)的阶段 性成果之一。

\section{REFERENCES}

[1] Information on http://www.360doc.com/document/ 17/1228/15/13611559_717141556.shtml

[2] J. Zhang. "The location, layout and historical position of Jinzhongdu Garden”, Beijing City Planning \& Construction, No. 4, pp. 105-111, 2014. (in Chinese)

[3] Y. Y. Wang. "Jinzhong capital: the beginning of Beijing's capital construction", The collection of the Forum on Chinese dream to prosper the history and culture of the ancient capital and realize the great rejuvenation of the Chinese nation, pp. 246-251, 2013. (in Chinese)

[4] D. P. Wang. "On the Features of Commercial Economy in Jin Dynasty", Journalof Liaoning University (Philosophy and Social Sciences), Vol.37, No, 3, pp. 83-88, 2009. (in Chinese)

[5] Information on http://www.360doc.com/document/ 13/0517/07/10106911_286001986.shtml 
[6] H. Zhang. "On the monetary system of the Jin Dynasty", Northern Finance Journal, No. S2, pp. 5-7, 2003. (in Chinese)

[7] D. W. Zeng. "The overview and comment of financial legislation of Jin Dynasty", Ethno-National Studies, No. 5, pp. 41-47, 1996. (in Chinese)

[8] S. Zhao. "The Construction of Jinzhongdu and the Festival Culture of Old Beijing", Beijing Culture Forum: a collection of papers on festivals and citizen life, pp. 14-15, Capital Normal University Press, Peking, 2013. (in Chinese) 